\title{
Critical speed and limit cycles in the empty Y25-freight wagon
}

\author{
H Molatefi ${ }^{1 *}$, M Hecht ${ }^{2}$, and M H Kadivar ${ }^{1}$ \\ ${ }^{1}$ Department of Mechanical Engineering, Shiraz University, Shiraz, Iran \\ ${ }^{2}$ Department of Rail Vehicles, TU-Berlin, Germany
}

The manuscript was received on 26 February 2006 and accepted after revision for publication on 25 April 2006.

DOI: 10.1243/09544097JRRT67

\begin{abstract}
In this research, an empty freight wagon with Y25 bogies have been modelled. Non-linear creep forces with spin moment between wheel and rail have been used, and also all impacts and friction forces have been modelled. Non-linear equations of motion and kinematical constraints have been solved in time domain, and limit cycles, saddle nodes, and critical speeds have been shown. Both primary and secondary hunting can be seen in the responses of the wagons. The relation between frequency of oscillations and speed can be seen, also, there are chaotic oscillations. Results show that stiffness in impacts affects calculation time and limit cycles.
\end{abstract}

Keywords: freight wagon, Y25 bogie, non-linear, hunting, limit cycle

\section{INTRODUCTION}

In the dynamics of rail vehicles limit cycles, chaos and bifurcation behaviour [1] appear and performances depend on initial conditions [2]. Pascal [3] simulated a derailment of a standard two-axle freight wagon in France and showed that the derailment might be connected with chaotic motions. In recent years, True et al. [4-8] have considered the nonlinear dynamics of rail vehicles and wheelsets with dry friction. They have showed that non-linearity in the suspension elements of rail vehicles can affect the hunting behaviour of the vehicle. Also, they have illustrated that the actual critical speed is less than linear critical speed, which can be evaluated by linear methods.

Suspension systems of conventional freight bogies have dry friction contacts [9] mainly because they are much cheaper than hydraulic dampers, and the damping force can be adjusted to the load by

*Corresponding author: Department of Mechanical Engineering, Shiraz University, PO Box 14515/1179, Shiraz, Iran. email: molatefi@iust.ac.ir or molatefi@gmail.com simple means. The disadvantages, however, are that the friction parts are open to the atmosphere, thus, they are influenced, for instance, by humidity and dirt and also by natural on wear. In addition to dry friction, impacts and also the contact between wheel and rail generate non-linear kinematical and dynamical terms $[\mathbf{1 0}, \mathbf{1 1}]$.

Y25 has been a UIC standard freight bogie since 1967 and is well designed for ratios of loaded to tare weight of $5: 1$. It originated from the Y21A designed by the French railway about 1960. In Y25, stiffness is load-dependent and the load-dependent friction damping is provided with Lenoir-Link (Fig. 1).

Empty wagons are one of the sources of noise in freight transportation. They have low critical speed and can oscillate with high amplitudes. In this research, completely non-linear equations of motions and constraints for the Y25-freight truck with empty wagons and 25 degrees of freedom have been derived. The property of primary suspension had been tested in TU-Berlin, all dry frictions have been modelled by the Kolch method, and impacts in clearances have been modelled by non-linear springs. Figure 2 shows the freight wagon with an 


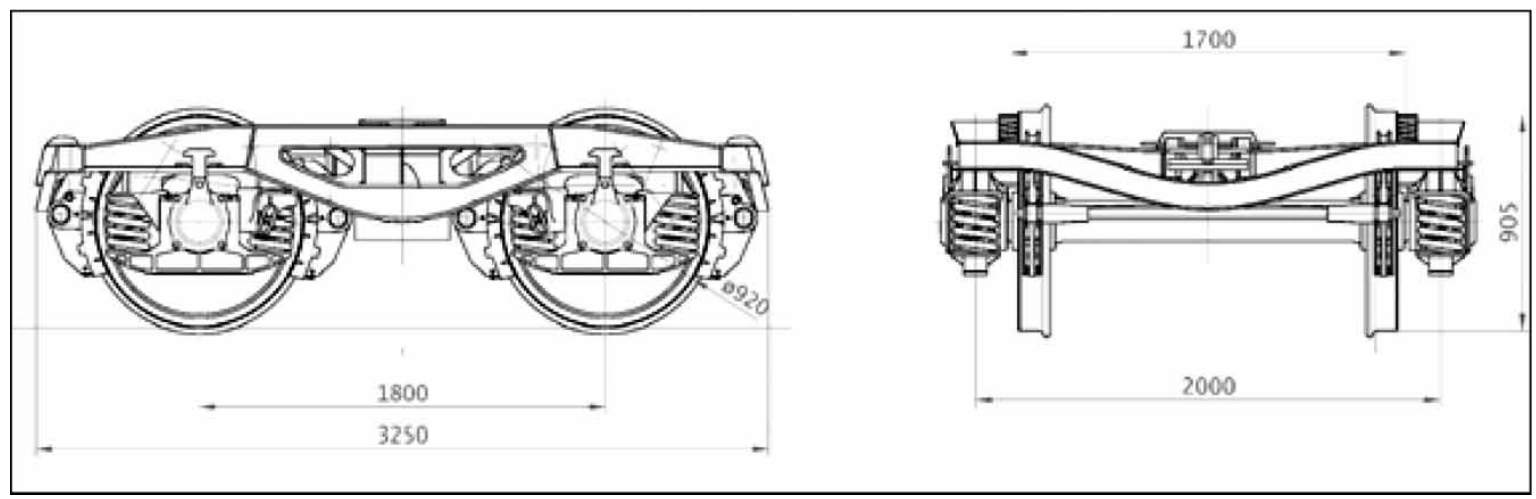

Fig. 1 Y25-freight bogie

Eaos807 carbody, and Table 1 shows the value of masses, the position for the centre of masses, and the moment of inertia for the empty wagon.

Wheel/rail contact creep coefficients and kinematical constraints have been derived by means of RSGEO software. Wheelset and rail have been defined in Table 2.

\section{SIMULATION OF FORCES}

\subsection{Wheel/Rail contact forces}

Several theories have been developed to approximate the creep forces between wheel and rail. Kalker's [10] linear theory was combined with JohnsonVermeulen's [10] non-linear theory by White et al. in 1978 to include the effect of spin creepage on non-linear creep forces $[\mathbf{1 2}, \mathbf{1 3}]$. The same method was proposed by Shen et al. in 1983 [10, 14], but in the method of White et al., the effects of the instantaneous normal force on creep coefficients was considered using a simple formula, and spin moment was calculated using Kalker's linear method. Nonlinear longitudinal $\left(F_{x}^{\prime}\right)$ and lateral creep forces $\left(F_{y}^{\prime}\right)$ and spin creep moment $M_{z}$ were defined as

$$
\begin{aligned}
& F_{x}^{\prime}=\varepsilon F_{x} \\
& F_{y}^{\prime}=\varepsilon F_{y} \\
& M_{z}=-f_{23} \xi_{y}+f_{33} \xi_{\mathrm{sp}}
\end{aligned}
$$

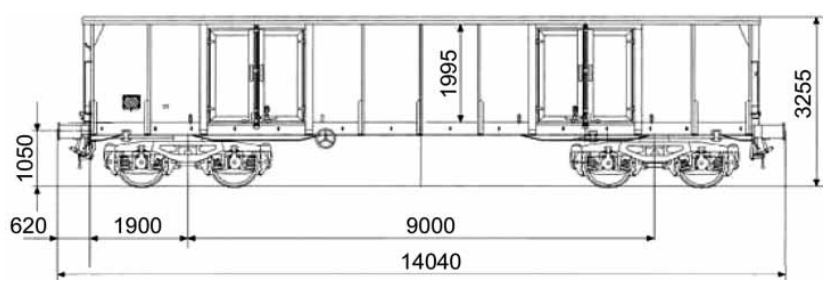

Fig. 2 Freight wagon with Eaos802 carbody where directions $(\mathrm{x}, \mathrm{y}, \mathrm{z})$ and creepage $\xi$ are in the 'contact coordinate system' and

$$
\begin{aligned}
F_{x} & =f_{11} \xi_{x} \\
F_{y} & =f_{22} \xi_{y}+f_{23} \xi_{\mathrm{sp}} \\
f_{11} & =\left(\frac{N}{N_{0}}\right)^{2 / 3} f_{110} \\
f_{23} & =\left(\frac{N}{N_{0}}\right) f_{230} \\
f_{22} & =\left(\frac{N}{N_{0}}\right)^{2 / 3} f_{220} \\
f_{33} & =\left(\frac{N}{N_{0}}\right)^{4 / 3} f_{330}
\end{aligned}
$$

where $N$ is the total instantaneous normal force and $N_{0}$ the total nominal normal force. $f_{i j}$ and $f_{i j 0}$ are creep coefficients that depend on the wheel and rail geometry, the material properties, and the normal force acting at the contact surface. $f_{i j 0}$ is the nominal value computed with nominal load $N_{0}$ using RSGEO software and $f_{i j}$ the corresponding value for instantaneous load $N$. The magnitude of the resultant creep force cannot exceed the pure slip value, $\mu N$, therefore, a creep force saturation coefficient, $\varepsilon$, is used

$$
\varepsilon= \begin{cases}\frac{\mu N}{F_{\mathrm{R}}}\left[\left(\frac{F_{\mathrm{R}}}{\mu N}\right)-\frac{1}{3}\left(\frac{F_{\mathrm{R}}}{\mu N}\right)^{2}+\frac{1}{27}\left(\frac{F_{\mathrm{R}}}{\mu N}\right)^{3}\right] & F_{\mathrm{R}} \leq 3 \mu N \\ \frac{\mu N}{F_{\mathrm{R}}} & F_{\mathrm{R}}>3 \mu N\end{cases}
$$

Where in $\mu=0.3$ and

$$
F_{\mathrm{R}}=\sqrt{F_{x}^{2}+F_{y}^{2}}
$$


Table 1 Mass, moment of inertia, and centre of mass for the Y25-freight truck

\begin{tabular}{|c|c|c|c|c|c|c|}
\hline \multirow[b]{2}{*}{ Y25 assembly } & \multirow[b]{2}{*}{ Centre of mass* (m) } & \multicolumn{3}{|c|}{ Moment of inertia $\left(\mathrm{kg} \mathrm{m}^{2}\right)$} & \multicolumn{2}{|c|}{ Mass [kg] } \\
\hline & & $\mathrm{Ixx}$ & Iyy & Izz & One unit & \\
\hline Wheelset with axle box & $h_{\mathrm{wh}}=0.46$ & 902 & 108 & 906 & 1380 & Bogie: 4750 \\
\hline Bogie & $h_{\mathrm{b}}=0.61$ & 1188 & 1484 & 2582 & 1990 & \\
\hline Carbody & $h_{\mathrm{c}}=1.31$ & 11389 & 219667 & 225378 & 11400 & \\
\hline Empty wagon & 0.9522 & & & & & \\
\hline
\end{tabular}

${ }^{*}$ Centre of mass is with respect to the railhead surface

\subsection{Forces in primary suspension}

In the Y25 freight bogie, the play between the axle box and the bogie frame in a vertical direction is roughly $55 \mathrm{~mm}$, in a lateral direction, $+/-10 \mathrm{~mm}$, and in a longitudinal direction there is a $4 \mathrm{~mm}$ play on one side. Impacts between parts, after clearances, have been modelled by non-linear springs with a high stiffness of $10^{7} \mathrm{~N} / \mathrm{m}$ (Fig. 3). The stiffness must be enough high to simulate solid contact and the effect of this high stiffness has been considered.

A measurement structure (Fig. 4) for the primary suspension system of Y25 has been developed in TU-Berlin [15]. Results show that there are hysteresis loops in three directions. Hysteresis can be assumed, as shown in Fig. 5, for different vertical preloads. Table 3 shows the results for a vertical load of $18.9 \mathrm{KN}$.

To model primary suspension force elements, the Kolsch method [16] has been used, explained in equation (6), in which the value $m$ denotes sharpness of diagram (Fig. 6) in the transition areas between stick and slip motions. Figure 6 shows force displacement in the vertical direction with $m=10$.

$$
\begin{aligned}
C_{0} & =C_{\mathrm{h}}-C_{\mathrm{g}} \\
\dot{K} & =C_{0} \dot{X}\left(1-0.5(\operatorname{sign}(\dot{X} K)+1)\left|\frac{2 K}{F_{D}}\right|^{m}\right) \\
F & =C_{g} X+K
\end{aligned}
$$

\subsection{Forces between carbody and bogies}

The bogie frame is connected to the carbody through a central pivot and side bearers [17]. Figure 7 shows

\begin{tabular}{|c|c|c|c|}
\hline $\begin{array}{l}\text { Wheel profile } \\
\text { S1002 }\end{array}$ & $\begin{array}{l}\text { Wheel base } \\
1800 \mathrm{~mm}\end{array}$ & $\begin{array}{l}\text { Wheelset tape } \\
\text { circle distance } \\
1500 \mathrm{~mm}\end{array}$ & $\begin{array}{l}\text { Wheel radius } \\
460 \mathrm{~mm}\end{array}$ \\
\hline Rail profile & Rail gauge & Inclination & Type \\
\hline UIC60 & $1435 \mathrm{~mm}$ & $1 / 40$ & $\begin{array}{l}\text { Straight/no } \\
\text { irregularities }\end{array}$ \\
\hline
\end{tabular}
the central pivot that is a spherical joint. The bogie

Table 2 Wheel and rail refinitions

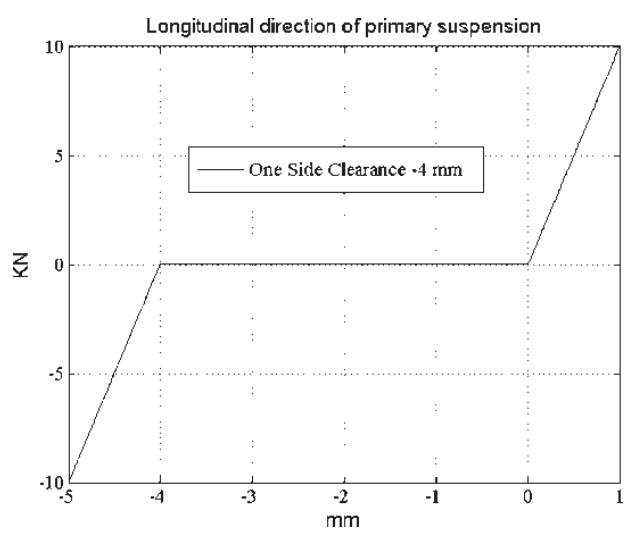

Fig. 3 Non-linear spring for axle box clearance in longitudinal direction

frame has angular motions about the joint centre with respect to the carbody. Contact surfaces and their relative motions generate dry friction in the central pivot. Researches and tests by Nielsen [18] show that the moments in the central pivot have maximum value, which can be evaluated as in equation (7). These values are in the slip mode, and in the stick mode the angular stiffness is about

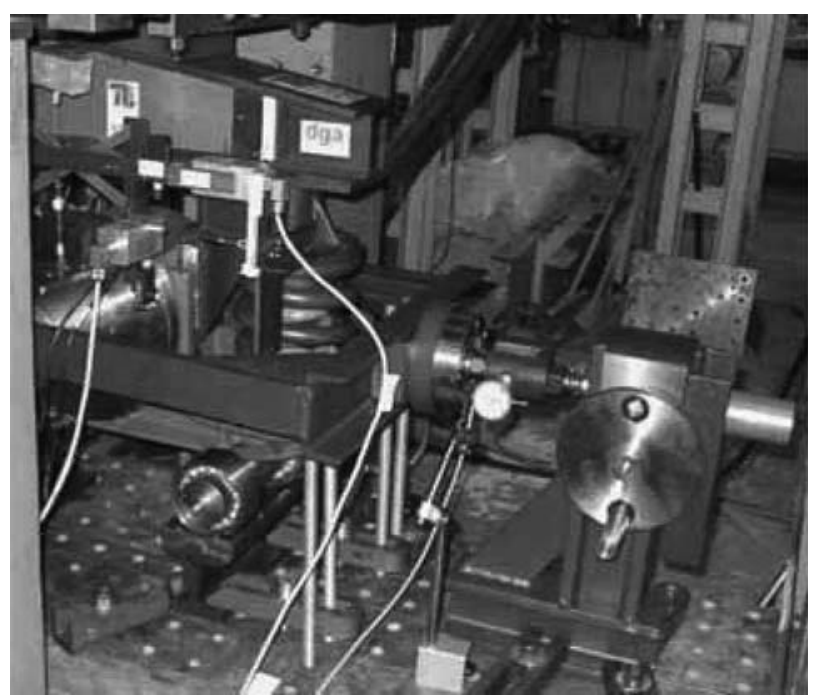

Fig. 4 Test structure for primary suspension of Y25 bogies 


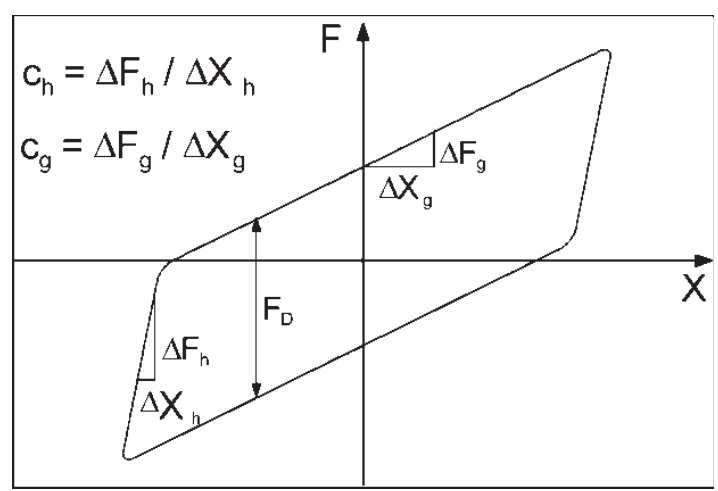

Fig. 5 Hysteresis in the force-displacement diagram

$10^{7} \mathrm{Nm} /$ Rad. 0.22 [17] has been used for dry friction coefficient.

$$
\begin{aligned}
& M_{x}=M_{y}=0.17 \cdot \mu_{\mathrm{CentPiv}} \cdot F_{N} \\
& M_{z}=0.18 \cdot \mu_{\mathrm{CentPiv}} \cdot F_{N}
\end{aligned}
$$

Figure 8 shows the spring loaded side bearer. The stiffness in the vertical direction is $5.7 \times 10^{5} \mathrm{~N} / \mathrm{m}$ and the preload is $16 \mathrm{KN}$. There is a $12 \mathrm{~mm}$ clearance play for springs. It is approximately equal to $0.014 \mathrm{rad}$ relative to the roll movement of the carbody and bogie. So, the minimum force on the side bearer is about $9160 \mathrm{~N}$, after $22840 \mathrm{~N}$ there will be solid contact. For damping in the vertical direction, $1000.0 \mathrm{Ns} / \mathrm{m}$ has been used [17]. Dry friction between the side bearers and the carbody has been modelled using the Kolsch method, with 0.22 for dry friction coefficient and $10^{6} \mathrm{~N} / \mathrm{m}$ for stick stiffness.

\section{EQUATIONS OF MOTIONS}

As is common, rotation around the longitudinal, lateral, and vertical axes have been defined as roll $(\varphi)$, pitch $(\chi)$, and yaw $(\psi)$. Wheelsets have four degrees of freedom (longitudinal, lateral, pitch, and yaw motions). Vertical and roll motions of wheelsets are dependent on the lateral and yaw motions of wheelsets and can be calculated from kinematical constraints between wheelset and track. Bogies have four degrees of freedom (lateral, vertical, roll, and yaw motions). The track is straight, without irregularity, and the pitch motion of the bogie frame can be ignored. The carbody (with bogies) is massive and,

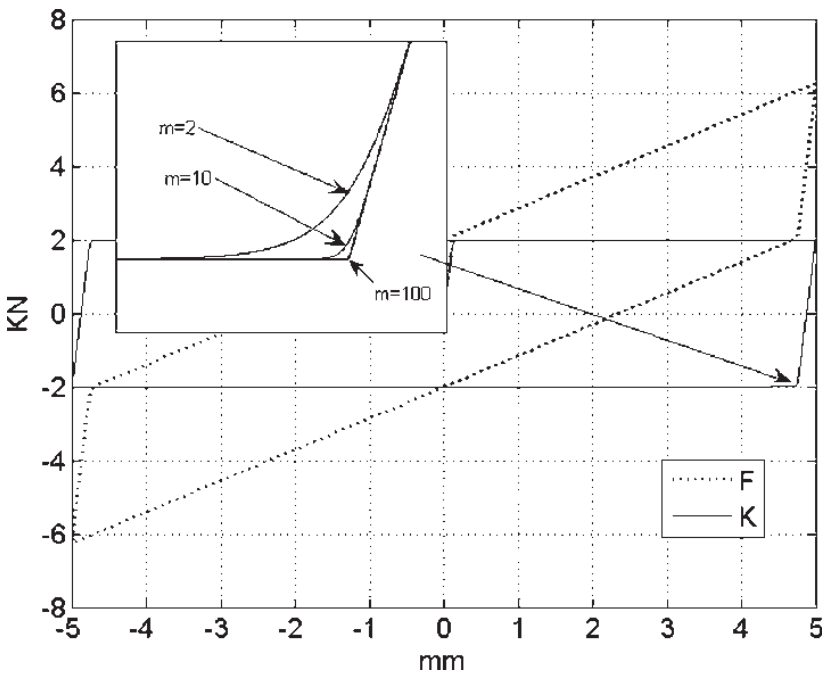

Fig. 6 Force-displacement in the vertical direction (Table 3)

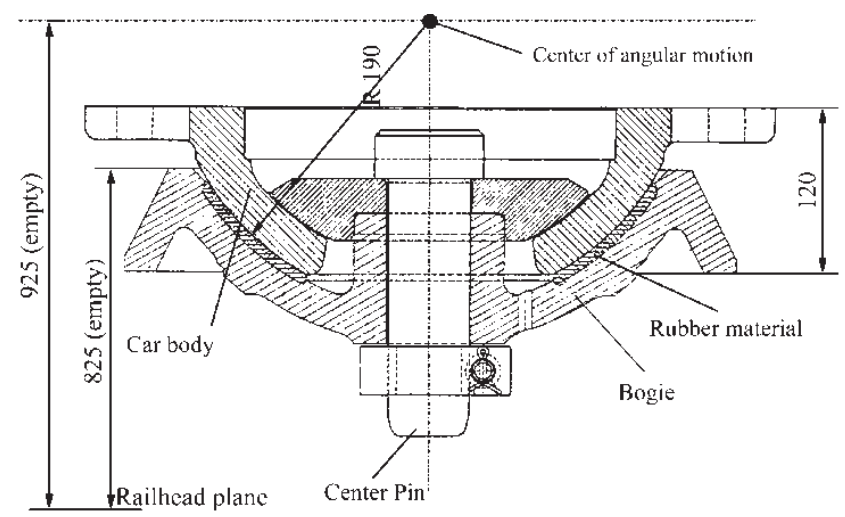

Fig. 7 Central pivot for Y25 Bogies (all dimensions in $\mathrm{mm}$ )

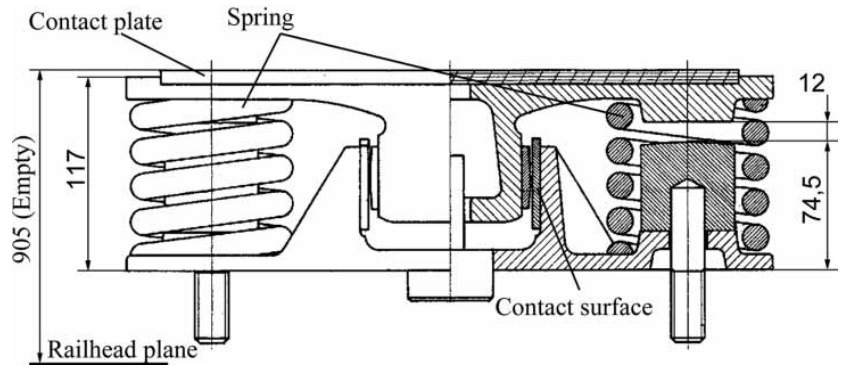

Fig. 8 Side bearer of Y25 (all dimensions in $\mathrm{mm}$ )

\begin{tabular}{|c|c|c|c|c|c|c|c|c|}
\hline \multicolumn{3}{|c|}{$\mathrm{x}$} & \multicolumn{3}{|c|}{$\mathrm{y}$} & \multicolumn{3}{|c|}{$\mathrm{z}$} \\
\hline $\mathrm{C}_{\mathrm{h}}(\mathrm{N} / \mathrm{m})$ & $\mathrm{C}_{\mathrm{g}}(\mathrm{N} / \mathrm{m})$ & $\mathrm{F}_{\mathrm{D}}(\mathrm{kN})$ & $\mathrm{C}_{\mathrm{h}}(\mathrm{N} / \mathrm{m})$ & $\mathrm{C}_{\mathrm{g}}(\mathrm{N} / \mathrm{m})$ & $\mathrm{F}_{\mathrm{D}}(\mathrm{kN})$ & $\mathrm{C}_{\mathrm{h}}(\mathrm{N} / \mathrm{m})$ & $\mathrm{C}_{\mathrm{g}}(\mathrm{N} / \mathrm{m})$ & $\mathrm{F}_{\mathrm{D}}(\mathrm{kN})$ \\
\hline $1.3 \times 10^{7}$ & $8.9 \times 10^{5}$ & 2.5 & $2.2 \times 10^{6}$ & $4.3 \times 10^{5}$ & 5.0 & $1.7 \times 10^{7}$ & $8.5 \times 10^{5}$ & 4.0 \\
\hline
\end{tabular}

Table 3 Test results for Y25 suspension in empty wagon 
therefore, acceleration can be ignored in the longitudinal direction. Longitudinal velocity is thus considered to be constant or known for bogies and carbody. Assuming the spherical joint in the central pivots of carbody reduces its freedom, it has one degree of freedom (roll motion) around the line connecting its central pivots.

For deriving equations of motion and constraint of this wagon, multiple coordinate systems have been used. Superscripts denote the coordinate systems and $r$ denotes the inertial coordinate system in the centreline of the track. Subscripts or superscripts 1, 2,3 , and 4 , have been used for the first, second, third, and fourth wheelsets, 5 and 6 have been used for the first and second bogie frame, and 7 has been used for the carbody (Fig. 9).

Equations of motions for wheelsets are as follows. Subscripts $\mathrm{cl}$ and $\mathrm{cr}$ denote left and right contact points, and $\mathrm{pl}$ and pr denote left and right primary suspensions, respectively. Also, $\tau_{\mathrm{c}}$ denotes movement around the centre of mass of wheelsets that is generated from forces of spin movement in the wheel/rail contact surface

$$
\begin{aligned}
& m_{\mathrm{w}} \ddot{x}_{i}=f_{i \mathrm{cl} x}^{r}+f_{i \mathrm{cr} x}^{r}+f_{i \mathrm{pl} x}^{r}+f_{i \mathrm{pr} x}^{r} \\
& m_{\mathrm{w}} \ddot{y}_{i}=f_{i \mathrm{cl} y}^{r}+f_{i \mathrm{cry} y}^{r}+f_{i \mathrm{pl} y}^{r}+f_{i \mathrm{pr} y}^{r} \\
& I_{\mathrm{w} y} \ddot{\chi}_{i}=\tau_{i y, \mathrm{cl}}^{i}+\tau_{i y, \mathrm{cr}}^{i} \\
& I_{\mathrm{w} z} \ddot{\psi}_{i}=\tau_{i z, \mathrm{cl}}^{i}+\tau_{i z, \mathrm{cr}}^{i}+a_{f} f_{i \mathrm{pr} x}^{i}-a_{f} f_{i \mathrm{pl} x}^{i}
\end{aligned}
$$

In simulations with curve radii larger than $200 \mathrm{~m}$, the effect of the wheelset's yaw motion on the geometrical parameters of wheel/rail contact is negligible [19]. In this research, simulations on a straight track have been considered and, therefore, geometrical parameters depend only on the lateral displacement of the wheelset. Vertical and roll motions versus lateral displacement of wheelset have been defined by RSGEO software

$$
\begin{aligned}
& m_{\mathrm{b}} \ddot{y}_{5}=-\left(f_{\mathrm{lpl} y}^{r}+f_{1 \mathrm{pr} y}^{r}+f_{2 \mathrm{ply}}^{r}+f_{2 \mathrm{pry}}^{r}\right) \\
& +f_{5 \mathrm{c} y}^{r}+f_{5 \mathrm{~s} l y}^{r}+f_{5 \mathrm{~s} r y}^{r} \\
& m_{\mathrm{b}} \ddot{z}_{5}=-\left(f_{1 \mathrm{pl} z}^{r}+f_{1 \mathrm{pr} z}^{r}+f_{2 \mathrm{plz}}^{r}+f_{2 \mathrm{prz}}^{r}\right) \\
& +f_{5 \mathrm{c} z}^{r}+f_{5 \mathrm{sl} z}^{r}+f_{5 \mathrm{si} z}^{r}-m_{\mathrm{b}} g \\
& I_{\mathrm{b} x} \ddot{\phi}_{5}=a_{f}\left(f_{1 \mathrm{pr} z}^{5}+f_{2 \mathrm{pr} z}^{5}-f_{1 \mathrm{plz}}^{5}-f_{2 \mathrm{plz} z}^{5}\right) \\
& -h_{f}\left(f_{1 \mathrm{pr} y}^{5}+f_{2 \mathrm{pr} y}^{5}+f_{1 \mathrm{ply}}^{5}+f_{2 \mathrm{ply}}^{5}\right) \\
& +a_{\mathrm{s}}\left(f_{5 \mathrm{~s} z}^{5}-f_{5 \mathrm{ssz}}^{5}\right)+\tau_{5 \mathrm{cx}}^{5}-h_{\mathrm{bc}} f_{5 \mathrm{c} y}^{5} \\
& I_{\mathrm{b} z} \ddot{\psi}_{5}=a_{f}\left(f_{1 \mathrm{pl} x}^{5}+f_{2 \mathrm{p} 1 x}^{5}-f_{1 \mathrm{pr} x}^{5}-f_{2 \mathrm{pr} x}^{5}\right) \\
& +l_{\mathrm{w}}\left(f_{2 \mathrm{pr} y}^{5}+f_{2 \mathrm{ply}}^{5}-f_{1 \mathrm{pr} y}^{5}-f_{1 \mathrm{ply} y}^{5}\right) \\
& +\tau_{5 \mathrm{cz}}^{5}+a_{\mathrm{s}}\left(f_{5 \mathrm{srt}}^{5}-f_{5 \mathrm{sl} t}^{5}\right)
\end{aligned}
$$

Equations of motion for the first bogie have been defined in equation (9), wherein sl and sr denote the left and right side bearers, respectively, and $\tau$ denotes the movement in the central pivot. Subscript $t$ is the friction force between side bearers and carbody (Fig. 10). Using the same method, the equations of motion for the second bogie is as shown in equation (10).

$$
\begin{aligned}
& m_{\mathrm{b}} \ddot{y}_{6}=-\left(f_{3 \mathrm{pl} y}^{r}+f_{3 \mathrm{pr} y}^{r}+f_{4 \mathrm{pl} y}^{r}+f_{4 \mathrm{pr} y}^{r}\right) \\
& +f_{6 \mathrm{c} y}^{r}+f_{6 \mathrm{~s} l y}^{r}+f_{6 \mathrm{sr} y}^{r} \\
& m_{\mathrm{b}} \ddot{z}_{6}=-\left(f_{3 \mathrm{pl} z}^{r}+f_{3 \mathrm{pr} z}^{r}+f_{4 \mathrm{plz}}^{r}+f_{4 \mathrm{pr} z}^{r}\right) \\
& +f_{6 \mathrm{c} z}^{r}+f_{6 \mathrm{sl} z}^{r}+f_{6 \mathrm{sr} z}^{r}-m_{\mathrm{b}} g \\
& I_{\mathrm{b} x} \ddot{\phi}_{6}=a_{f}\left(f_{3 \mathrm{pr} z}^{6}+f_{4 \mathrm{pr} z}^{6}-f_{3 \mathrm{pl} z}^{6}-f_{4 \mathrm{pl} z}^{6}\right) \\
& -h_{f}\left(f_{3 \mathrm{pr} y}^{6}+f_{4 \mathrm{pr} y}^{6}+f_{3 \mathrm{ply}}^{6}+f_{4 \mathrm{ply} y}^{6}\right) \\
& +a_{\mathrm{s}}\left(f_{6 \mathrm{sl} z}^{6}-f_{6 \mathrm{sr} z}^{6}\right)+\tau_{6 \mathrm{c} x}^{6}-h_{\mathrm{bc}} f_{6 \mathrm{c} y}^{6}
\end{aligned}
$$

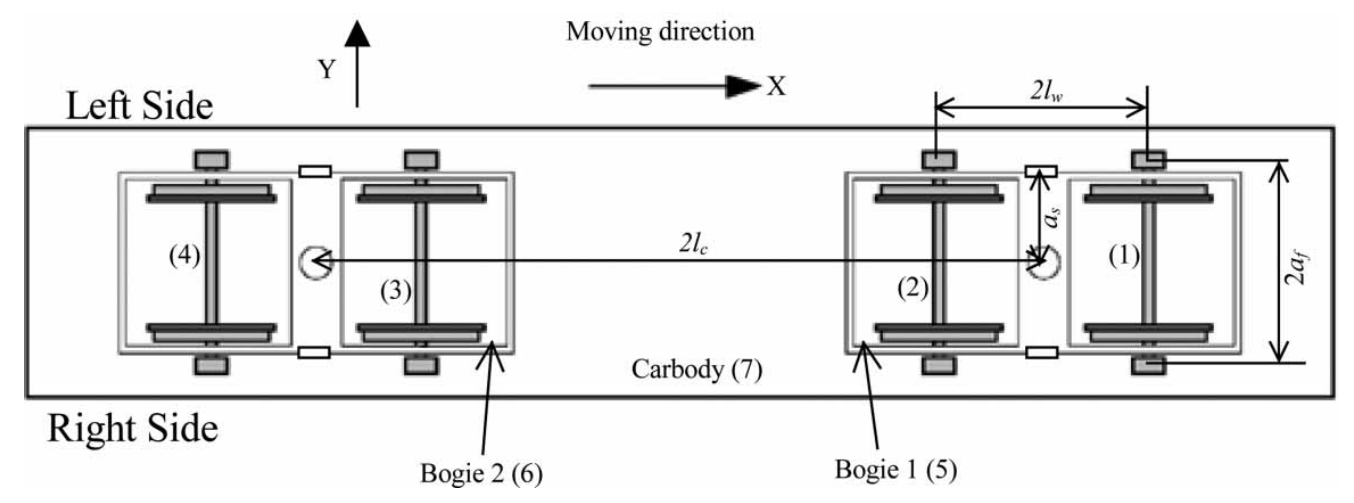

Fig. 9 Top view of the wagon 


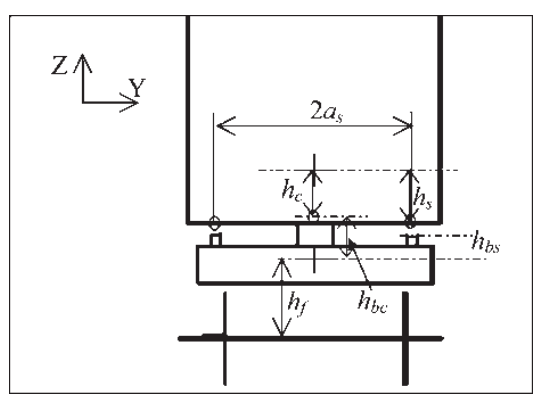

Fig. 10 Front view of the wagon

$$
\begin{aligned}
I_{\mathrm{b} z} \ddot{\psi}_{6}= & a_{f}\left(f_{3 \mathrm{pl} x}^{6}+f_{4 \mathrm{pl} x}^{6}-f_{3 \mathrm{pr} x}^{6}-f_{4 \mathrm{pr} x}^{6}\right) \\
& +l_{\mathrm{w}}\left(f_{4 \mathrm{pr} y}^{6}+f_{4 \mathrm{pl} y}^{6}-f_{3 \mathrm{pr} y}^{6}-f_{3 \mathrm{ply}}^{6}\right) \\
& +\tau_{6 \mathrm{ccz}}^{6}+a_{\mathrm{s}}\left(f_{6 \mathrm{sr} t}^{6}-f_{6 \mathrm{sl} t}^{6}\right)
\end{aligned}
$$

As mentioned before, the central pivots of the carbody generate constraints that can be explained approximately as (11). With these constraints, the equations of motion for the carbody are as shown in (12) (Fig. 10).

$$
\begin{aligned}
& y_{7}^{r}=\frac{\left(y_{6}^{r}+y_{5}^{r}\right)}{2} \\
& z_{7}^{r}=\frac{\left(z_{6}^{r}+z_{5}^{r}\right)}{2} \\
& \chi_{7}^{r}=\frac{\left(z_{6}^{r}-z_{5}^{r}\right)}{2 l_{\mathrm{c}}} \\
& \psi_{7}^{r}=\frac{\left(y_{5}^{r}-y_{6}^{r}\right)}{2 l_{\mathrm{c}}} \\
& m_{\mathrm{c}} \ddot{y}_{7}=-\left(f_{5 \mathrm{c} y}^{r}+f_{5 \mathrm{~s} l y}^{r}+f_{\mathrm{sry}}^{r}+f_{6 \mathrm{c} y}^{r}+f_{6 \mathrm{sly}}^{r}+f_{6 \mathrm{ssr} y}^{r}\right) \\
& m_{\mathrm{c}} \ddot{z}_{7}=-\left(f_{5 \mathrm{c} z}^{r}+f_{5 \mathrm{sl} z}^{r}+f_{5 \mathrm{srz} z}^{r}+f_{6 \mathrm{cc} z}^{r}+f_{6 \mathrm{slz} z}^{r}+f_{6 \mathrm{srz}}^{r}\right)-m_{\mathrm{c}} g \\
& I_{c x} \ddot{\phi}_{7}=\left(I_{\mathrm{c} y}-I_{\mathrm{c} z}\right) \dot{\chi}_{7} \dot{\psi}_{7}-\tau_{5 \mathrm{c} x}^{7}-\tau_{6 c x}^{7}-h_{\mathrm{c}}\left(f_{5 \mathrm{c} y}^{7}+f_{6 \mathrm{cy} y}^{7}\right) \\
& +a_{\mathrm{s}}\left(f_{5 \mathrm{srz} z}^{7}-f_{5 \mathrm{slz} z}^{7}+f_{6 \mathrm{ssz}}^{7}-f_{6 \mathrm{slz} z}^{7}\right) \\
& I_{\mathrm{c} y} \dot{\chi}_{7}=\left(I_{\mathrm{c} z}-I_{\mathrm{c} x}\right) \dot{\phi}_{7} \dot{\psi}_{7}+l_{\mathrm{c}}\left(f_{5 \mathrm{c} z}^{7}+f_{5 \mathrm{sl} z}^{7}+f_{5 s r z}^{7}\right. \\
& \left.-f_{6 \mathrm{cz} z}^{7}-f_{\mathrm{slz}}^{7}-f_{6 \mathrm{szz}}^{7}\right)+h_{\mathrm{c}}\left(f_{5 \mathrm{cx}}^{7}+f_{6 \mathrm{cx}}^{7}\right) \\
& +h_{\mathrm{s}}\left(f_{5 \mathrm{sl} t}^{7}+f_{5 \mathrm{sr} t}^{7}+f_{6 \mathrm{sil} t}^{7}+f_{\mathrm{srt}}^{7}\right)-\tau_{5 \mathrm{cy}}^{7}-\tau_{6 \mathrm{cc} y}^{7} \\
& I_{\mathrm{cz}} \ddot{\psi}_{7}=\left(I_{\mathrm{c} x}-I_{\mathrm{c} y}\right) \dot{\chi}_{7} \dot{\phi}_{7}+a_{\mathrm{s}}\left(f_{5 \mathrm{sl} t}^{7}-f_{5 \mathrm{srt}}^{7}+f_{6 \mathrm{sl} t}^{7}-f_{6 \mathrm{srt}}^{7}\right) \\
& +l_{\mathrm{c}}\left(f_{6 \mathrm{c} y}^{7}-f_{5 \mathrm{c} y}^{7}\right)-\tau_{5 \mathrm{c} z}^{7}-\tau_{6 \mathrm{c} z}^{7}
\end{aligned}
$$

\section{RESULTS}

Normally, critical speed refers to the non-linear critical speed in the railway vehicle system dynamics. The non-linear critical speed is the lowest speed for which a periodical motion exists, and it will be determined by bifurcation analysis. Periodical motions appear with two saddle-node bifurcations. The velocity of the first saddle-node bifurcation is the non-linear critical velocity, which can be found by driving the perturbed vehicle at a velocity sufficiently higher than the critical speed. After some time, the solution will be converged to a limit cycle oscillation. The next step is an adiabatic reduction of the velocity, which can be done by making the velocity a linear function of time. This reduction is done until passing the saddle node, which is clearly seen because the amplitude of the oscillation suddenly drops to zero.

The dynamical systems of Y25-freight trucks are very complicated because of the non-smoothness and the discontinuities caused by impacts and the stick-slip motions originating from clearance and dry friction. The time for computation of the necessary data for fine visualization of bifurcation is very long. To find the limit cycles for non-linear systems, there is no unique method. In this research, wagon perturbation was simulated at different speeds (starting from $1.0 \mathrm{~m} / \mathrm{s}$, with step size of $1.0 \mathrm{~m} / \mathrm{s}$ ). With this method, limit cycles can be seen and saddle nodes can be found as a jump in the limit cycle amplitude. To find the other saddle node, the vehicle speed was simulated at a speed more than that with jumped amplitudes. After $25 \mathrm{~s}$, the speed was decreased linearly until the amplitude of oscillations became zero. In addition, the speed was increased to find the behaviour of the vehicle at speeds more than critical speed.

\subsection{Critical speed}

Figure 11 shows the amplitude for limit cycles in different speeds and, as can be seen, the limit cycle appears in $21 \mathrm{~m} / \mathrm{s}$. There is a jump in the amplitude at a speed of $25 \mathrm{~m} / \mathrm{s}$.

More detailed simulations between 20 and $21 \mathrm{~m} / \mathrm{s}$ and also between 24 and $25 \mathrm{~m} / \mathrm{s}$ show that the limit cycle starts from $20.9 \mathrm{~m} / \mathrm{s}$ and an excessive amplitude appears in $24.1 \mathrm{~m} / \mathrm{s}$.

To find the critical speed, simulation was started from a speed of $30 \mathrm{~m} / \mathrm{s}$ and after $10 \mathrm{~s}$ the speed was reduced $0.02 \mathrm{~m} / \mathrm{s}$. The simulation was done for $910 \mathrm{~s}$ and with 18200000 loops. Non-linear critical speed for this wagon with Y25 bogie is $17 \mathrm{~m} / \mathrm{s}$ $(61.2 \mathrm{~km} / \mathrm{h})$. As Fig. 12 shows, all lateral displacements jumps down in $17 \mathrm{~m} / \mathrm{s}$ Fig. 12 shows the change in the limit cycle diagram of the carbody with a change in the speed.

In Fig. 13 the positions of two saddle-nodes can be seen. The first one, or the critical speed, is attained in $17 \mathrm{~m} / \mathrm{s}$ and the second one in about $24.0 \mathrm{~m} / \mathrm{s}$. The speed $20.9 \mathrm{~m} / \mathrm{s}$ is known as linear 

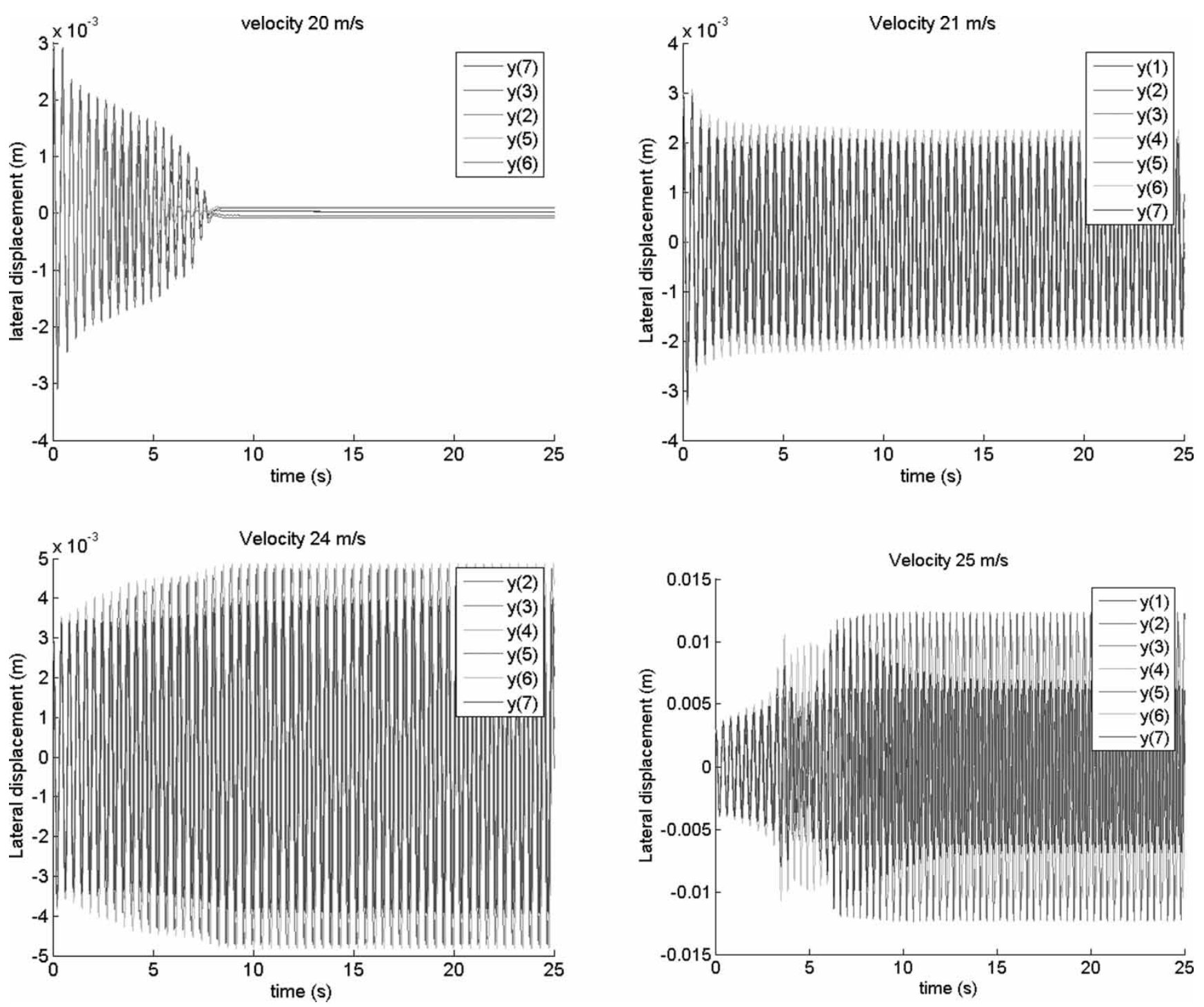

Fig. 11 Search for limit cycles in different speeds
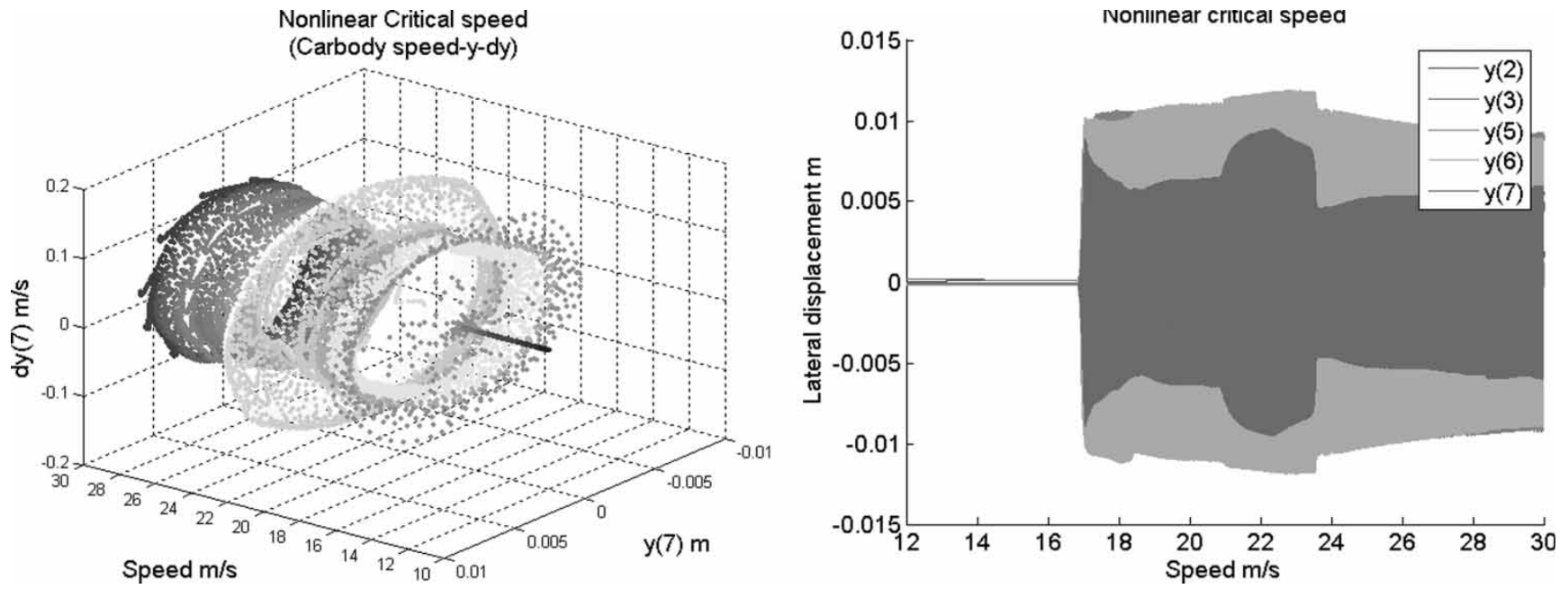

Fig. 12 Non-linear critical speed for the wagon with Y25 Bogie 

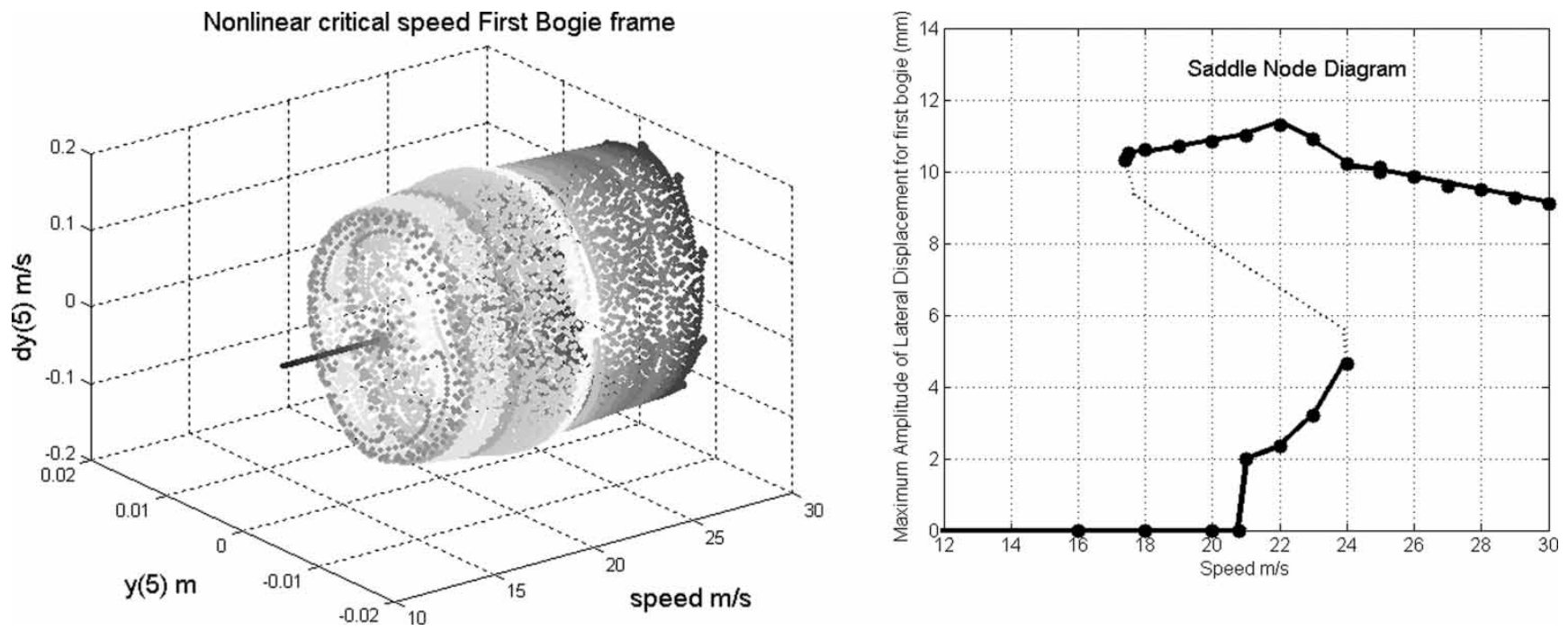

Fig. 13 Non-linear critical speed and saddle nodes
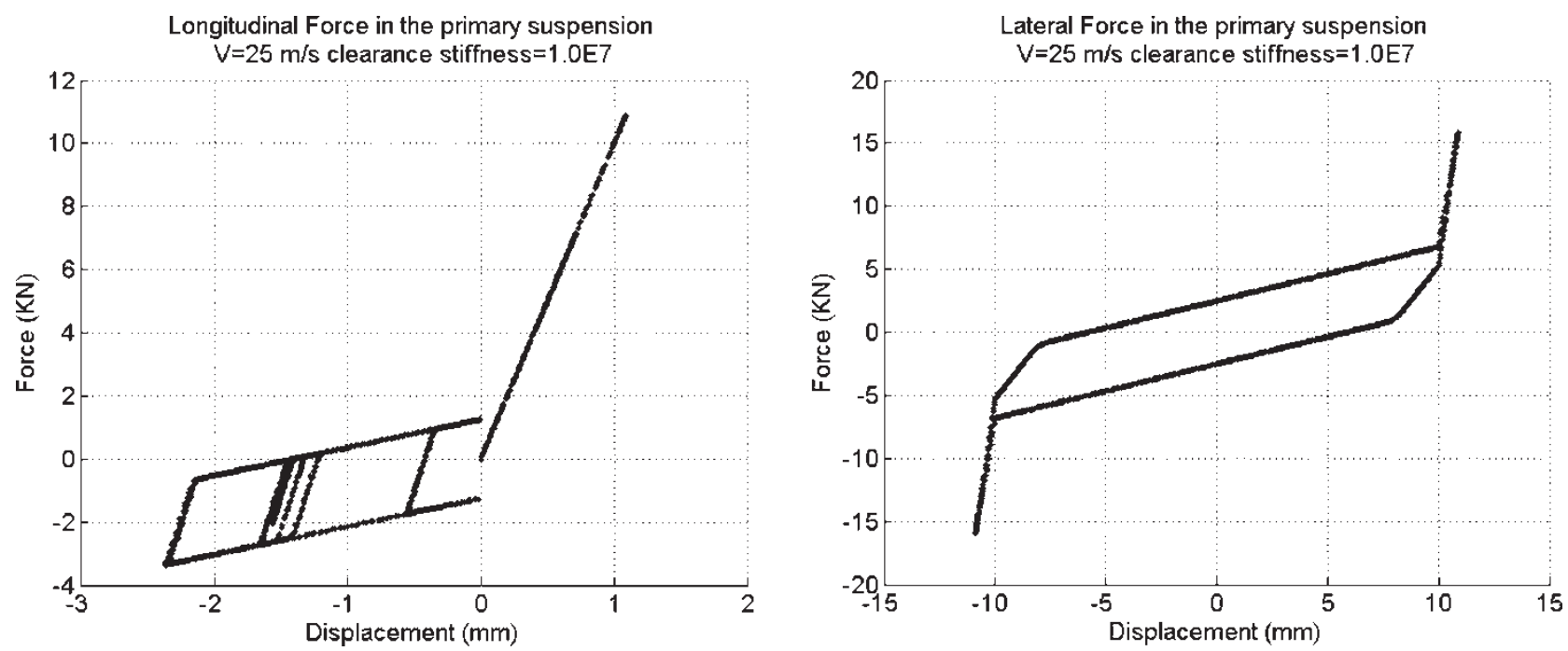

Fig. 14 Longitudinal and lateral forces in the primary suspension system
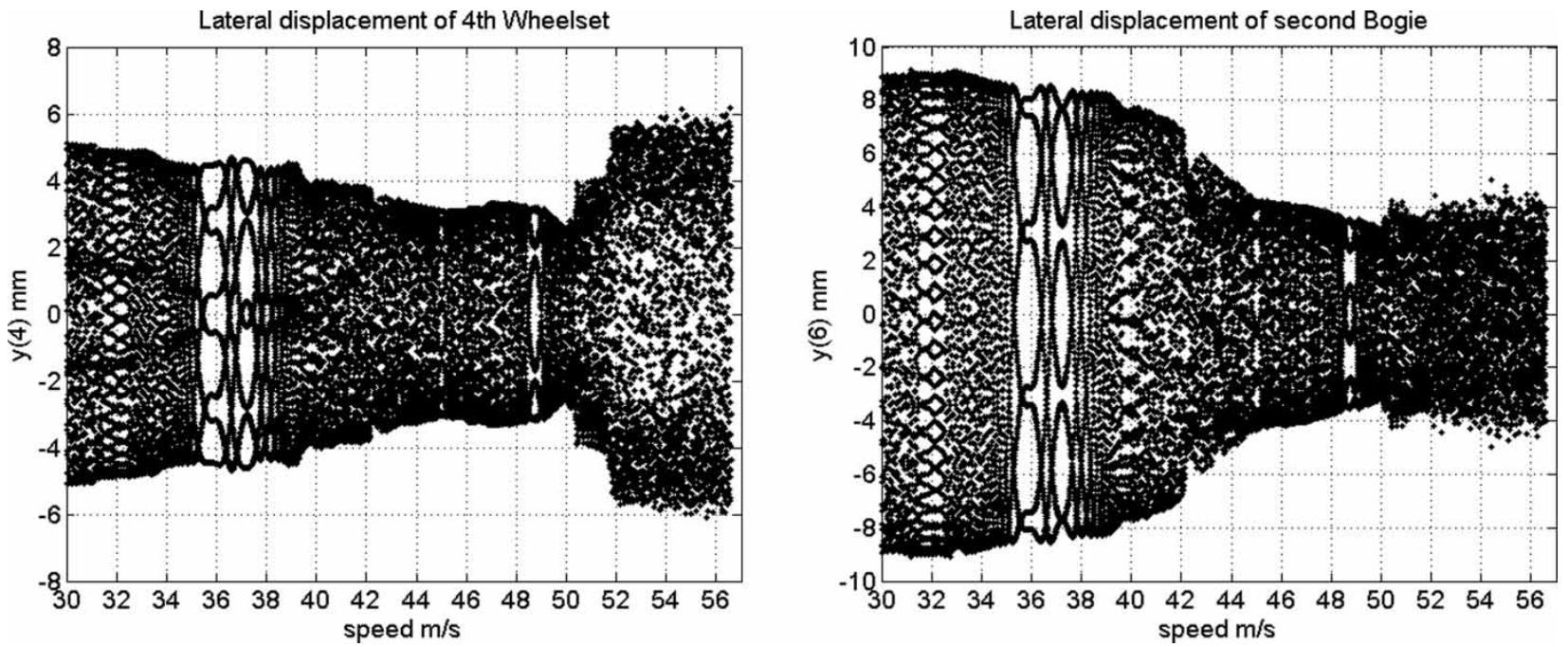

Fig. 15 Changes of lateral displacements in limit cycles by speed 
critical speed, and it is more than non-linear critical speed.

Figure 14 shows force-displacement loops for the primary suspension system in the left side of the
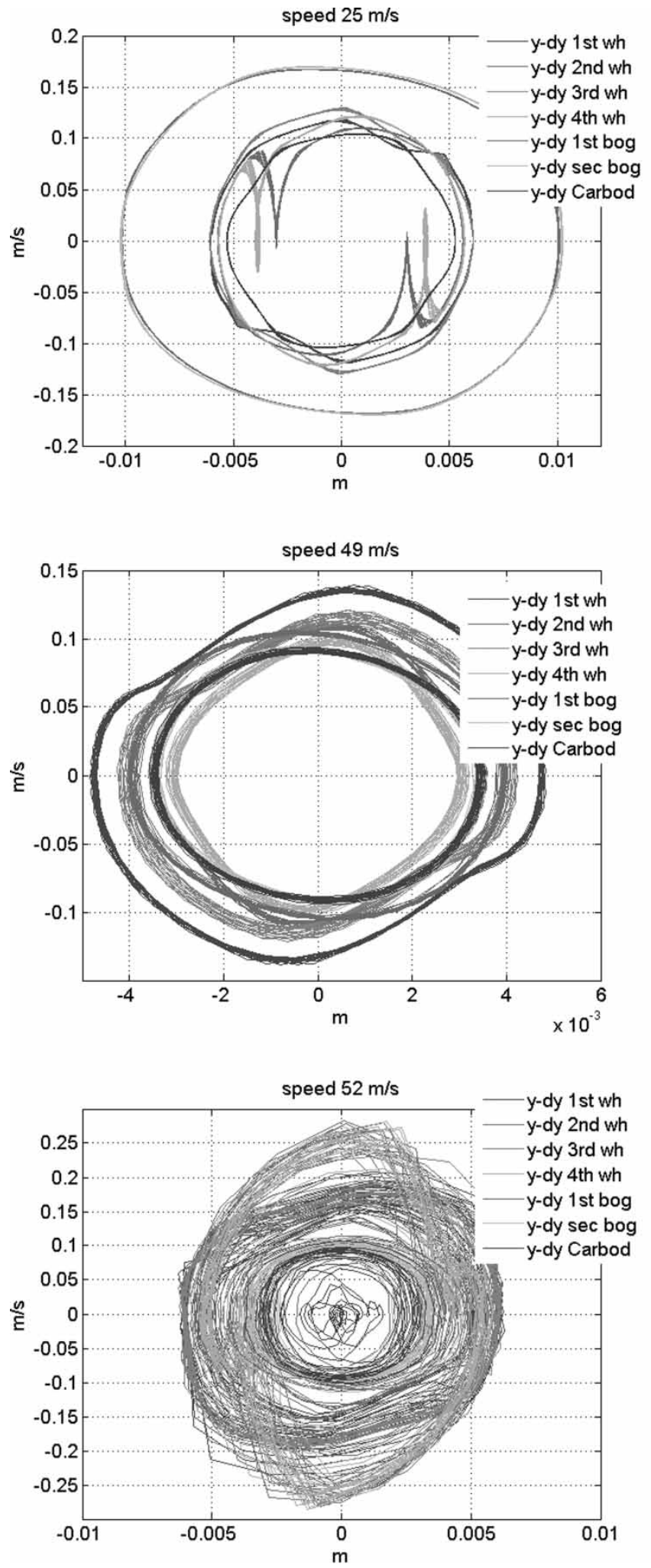

second and fourth wheelsets at $25 \mathrm{~m} / \mathrm{s}$ (for the last $5 \mathrm{~s}$ of Fig. 11). The damping source is dry friction and the hysteresis loops can be seen in the figure. The effect of one-side clearance $(-4 \mathrm{~mm})$ for primary
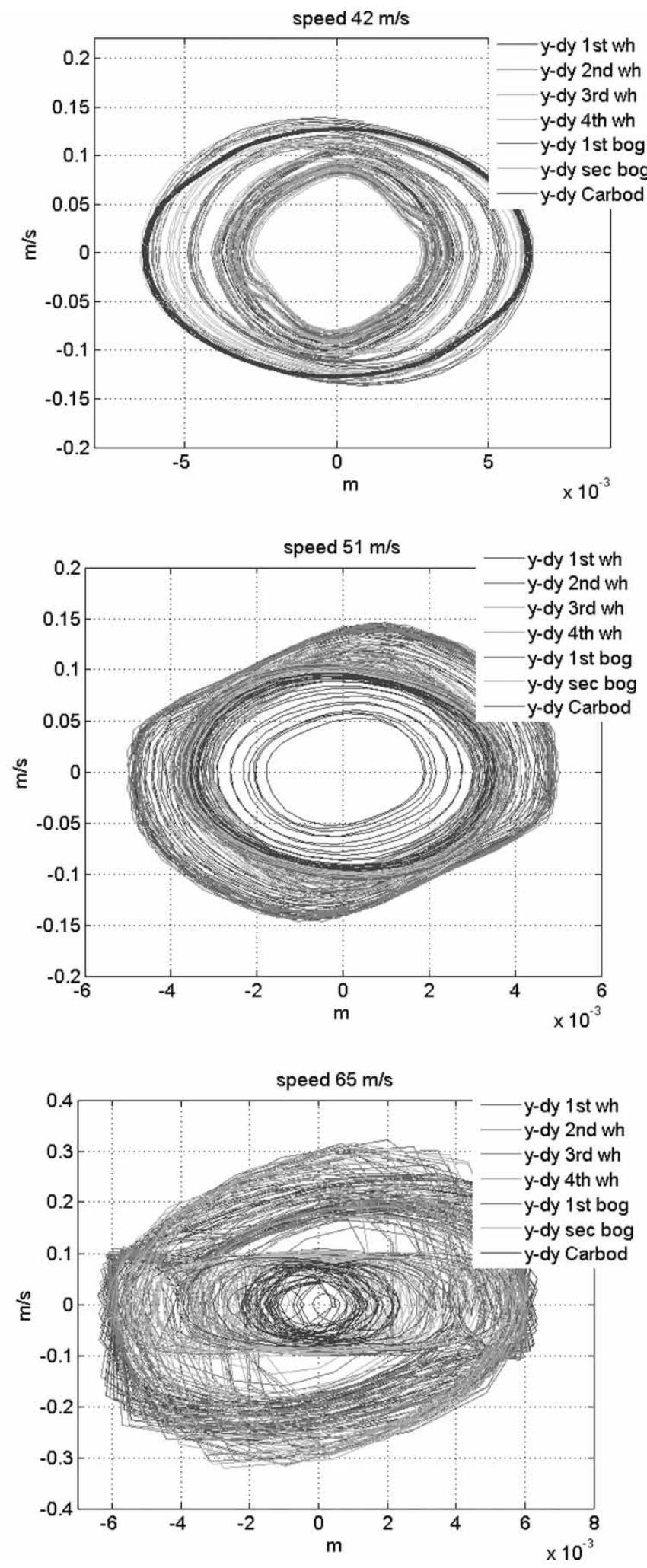

Fig. 16 State-space diagrams for limit cycles in different speed 
suspension of Y25 can be seen. After, solid impact stiffness of $1.0 \mathrm{E} 7 \mathrm{~N} / \mathrm{m}$ has been used. Figure 14 shows that after $10 \mathrm{~mm}$ lateral displacement, there is solid impact.

\subsection{Changes in limit cycles by speed}

Figure 15 shows lateral displacements in limit cycles between 30 and $57 \mathrm{~m} / \mathrm{s}$. By increasing the speed, limit cycles change, and after about $52 \mathrm{~m} / \mathrm{s}$ oscillations are chaotic. These chaotic motions diverge at a speed of about $56.3 \mathrm{~m} / \mathrm{s}$ with a time step of 5.0E-5 sec. Figure 16 shows limit cycles in different speeds. These results have been calculated by running $25 \mathrm{~s}$ with perturbed vehicle. All diagrams in Fig. 16 are the last $5 \mathrm{~s}$ of calculations. From critical speed up to $30.0 \mathrm{~m} / \mathrm{s}$, lateral displacement of bogies is about $1 \mathrm{~cm}$. Bogie frames have maximum lateral oscillations from all bodies. This kind of oscillation is known as primary hunting. Chaotic behaviour appears around $42 \mathrm{~m} / \mathrm{s}$ and after $52 \mathrm{~m} / \mathrm{s}$.

There are wheel-flange contacts with huge forces after $52.0 \mathrm{~m} / \mathrm{s}$; so, after $56.3 \mathrm{~m} / \mathrm{s}$, time steps for simulations must be $<1.0 \mathrm{E}-5 \mathrm{~s}$. After $49 \mathrm{~m} / \mathrm{s}$, wheelsets have maximum lateral displacements. This kind of oscillation is known as secondary hunting.

\subsection{Frequencies for limit cycles}

With regard to the Klingel [20] theory, for a simple wheelset with coned wheels that runs on a knifeedge straight track, and where the track is two parallel lines, there is a direct relation between speed and frequency of oscillation (frequency $\propto$ speed). The author's model is completely different and complex, but there is dependency between the speed and frequency. Figure 17 shows lateral oscillations and its power spectrum for the second bogie frame between 20 and $21 \mathrm{~s}$. As the figure shows, by increasing speed, the frequency of oscillations is increased. This model differs from that in the Klingel theory mainly in vehicle dynamics, profiled wheels, and profiled rails.

For $22 \mathrm{~m} / \mathrm{s}$, there are two limit cycles. In the second limit cycle, the lateral amplitude for wheelsets is about $6 \mathrm{~mm}$. Therefore, the high forces act on the flanges of wheels and increase the frequency of oscillations.

\subsection{Effect of clearance stiffness}

The stiffness Kclear $=1.0 \mathrm{E} 7 \mathrm{~N} / \mathrm{m}$ has been used for solid impacts between parts. Figure 18 shows forcedisplacement diagrams in the primary suspension system. For Kclear $=10.0 \mathrm{E} 7 \mathrm{~N} / \mathrm{m}$ and $\mathrm{V}=25 \mathrm{~m} / \mathrm{s}$
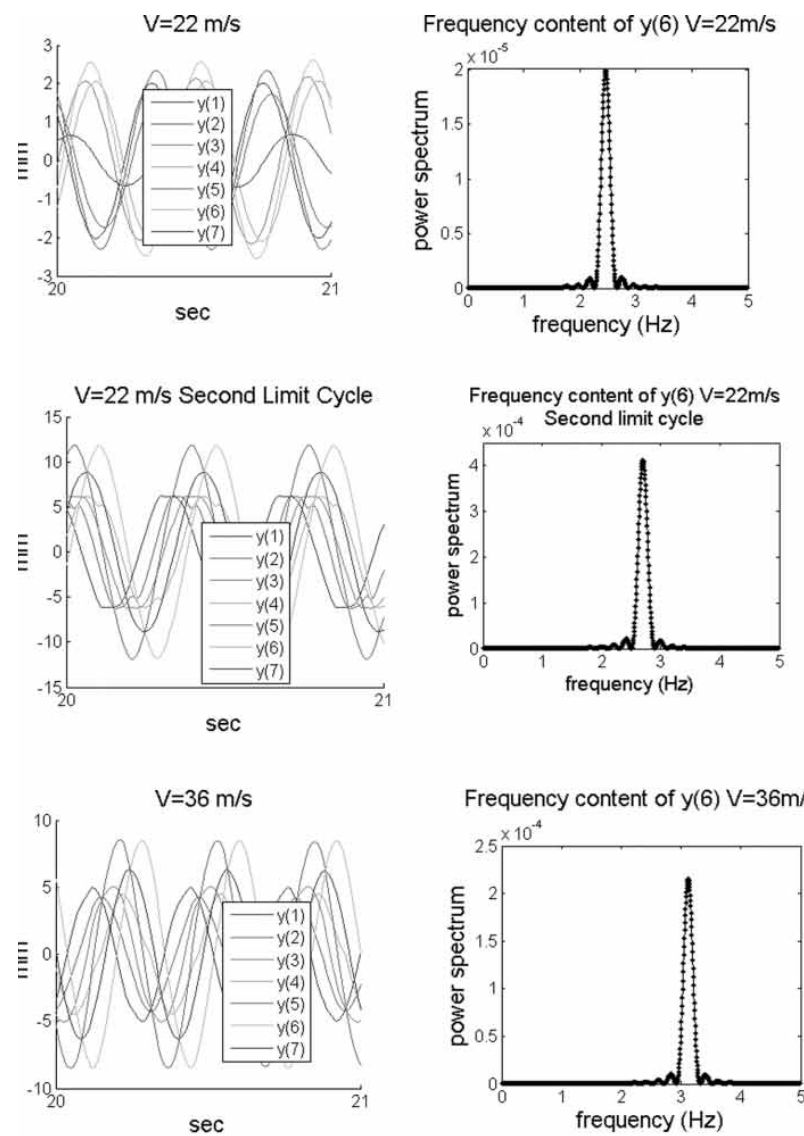

Frequency content of $y(6) \mathrm{V}=36 \mathrm{~m} / \mathrm{s}$
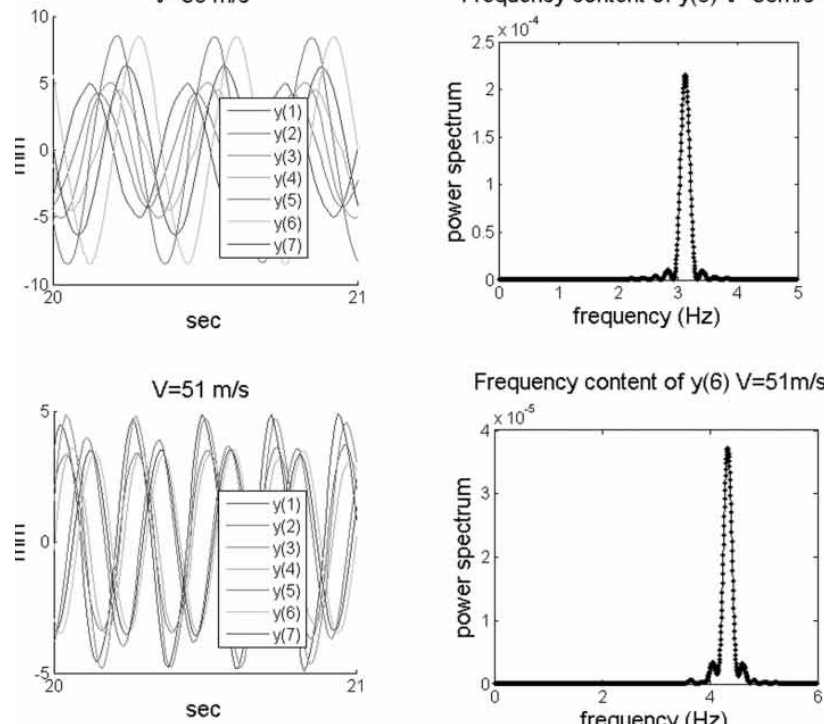

Frequency content of $y(6) \mathrm{V}=51 \mathrm{~m} / \mathrm{s}$
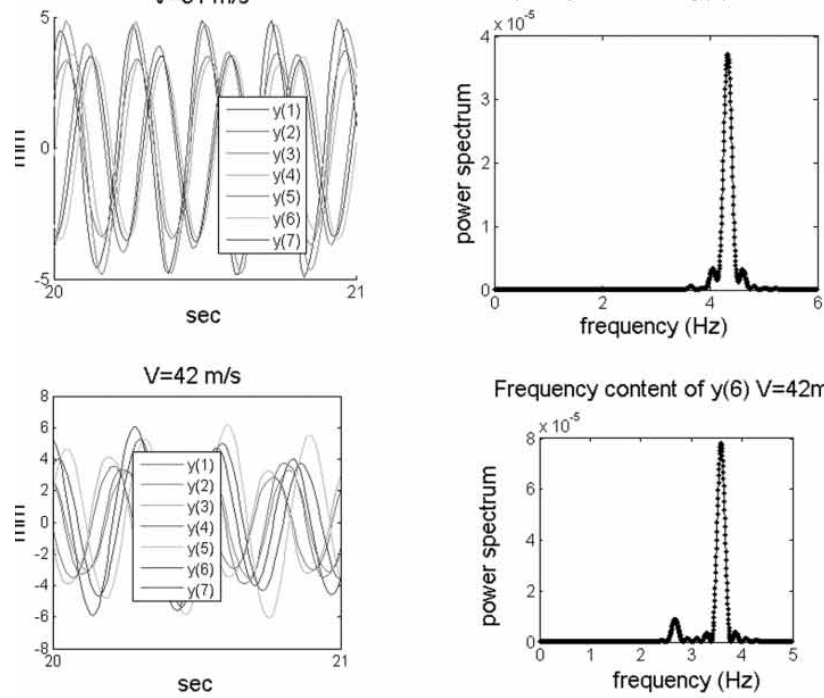

Frequency content of $y(6) V=42 \mathrm{~m} / \mathrm{s}$
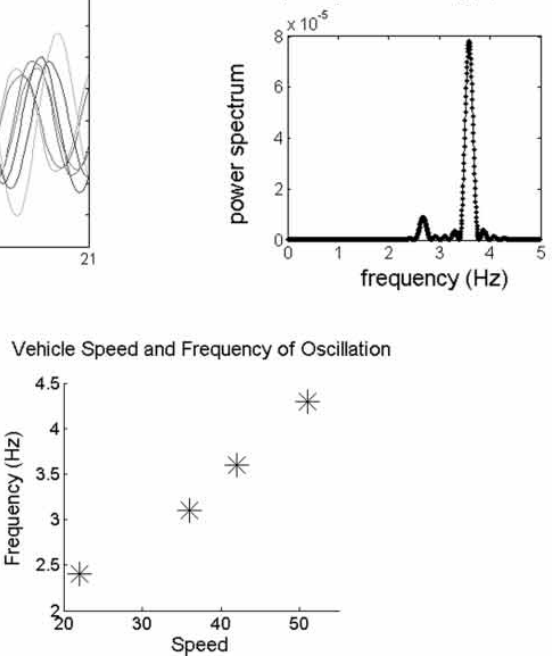

Fig. 17 lateral displacement in the limit cycles and related frequencies 

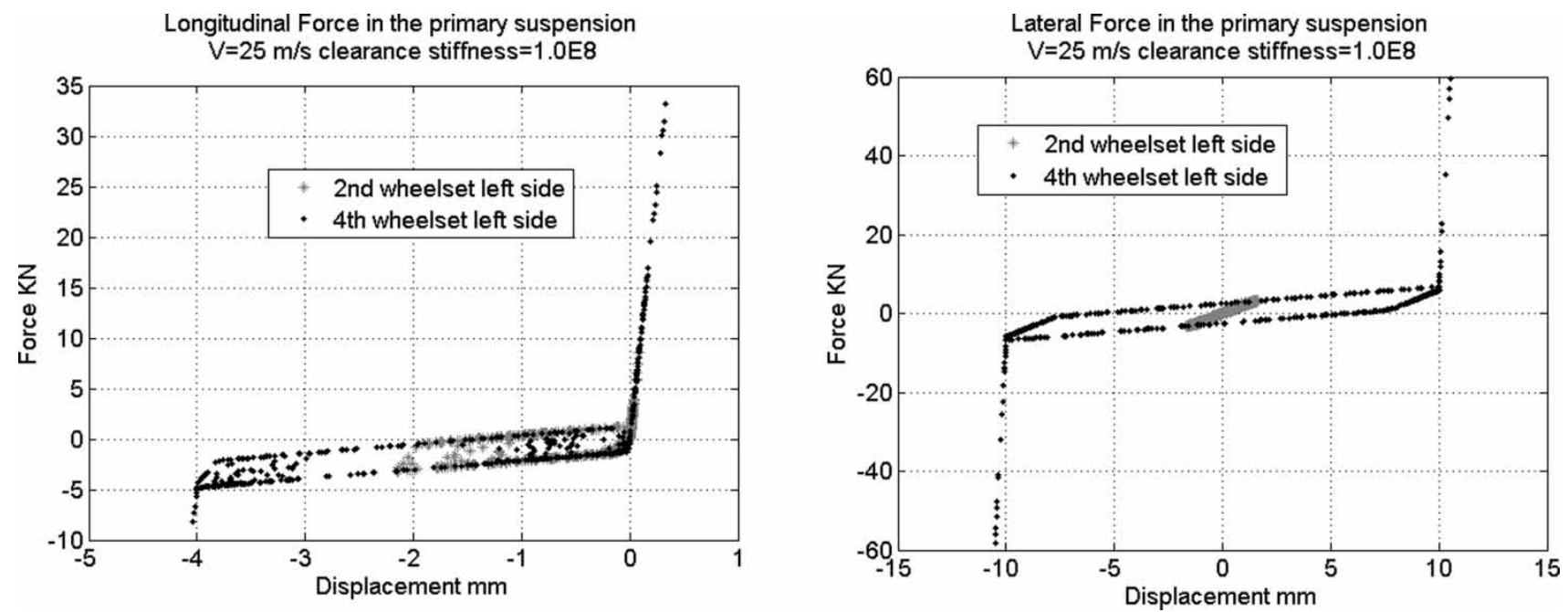

Fig. 18 Longitudinal and lateral force in the primary suspension system
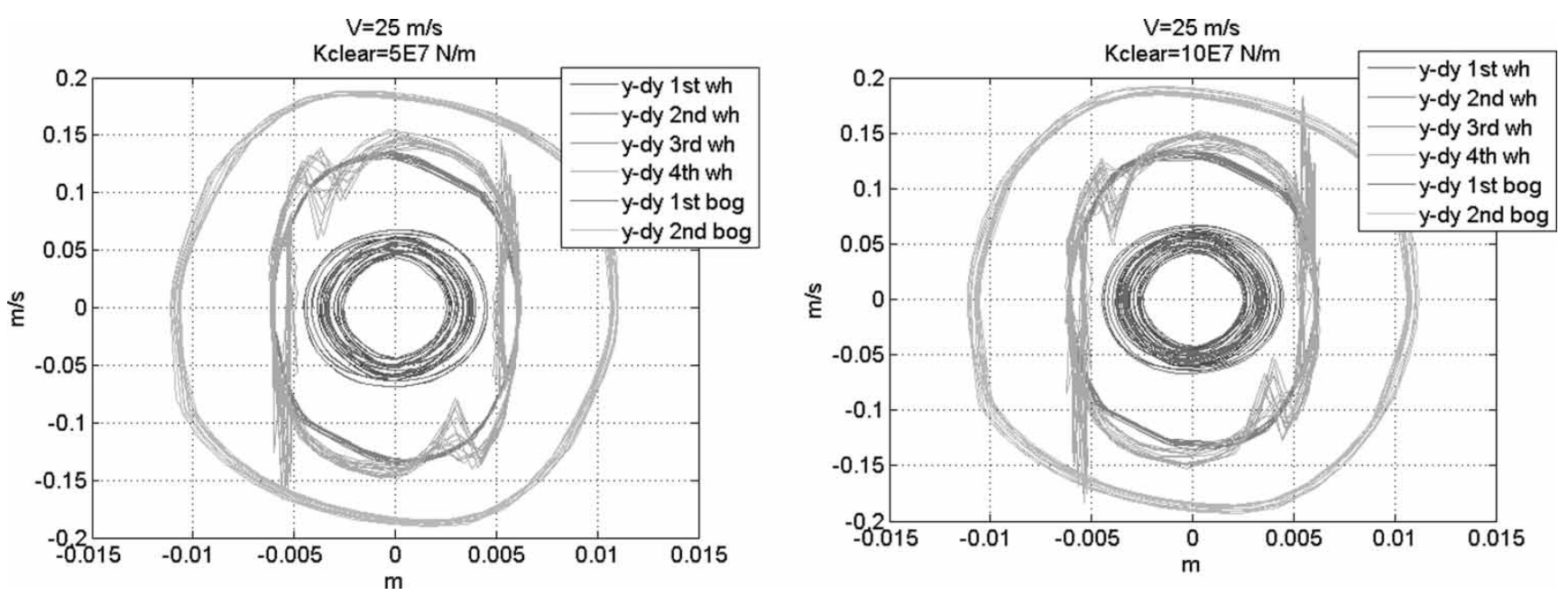

Fig. 19 Effect of Kclear in the lateral oscillation of first bogie $V=25 \mathrm{~m} / \mathrm{s}$
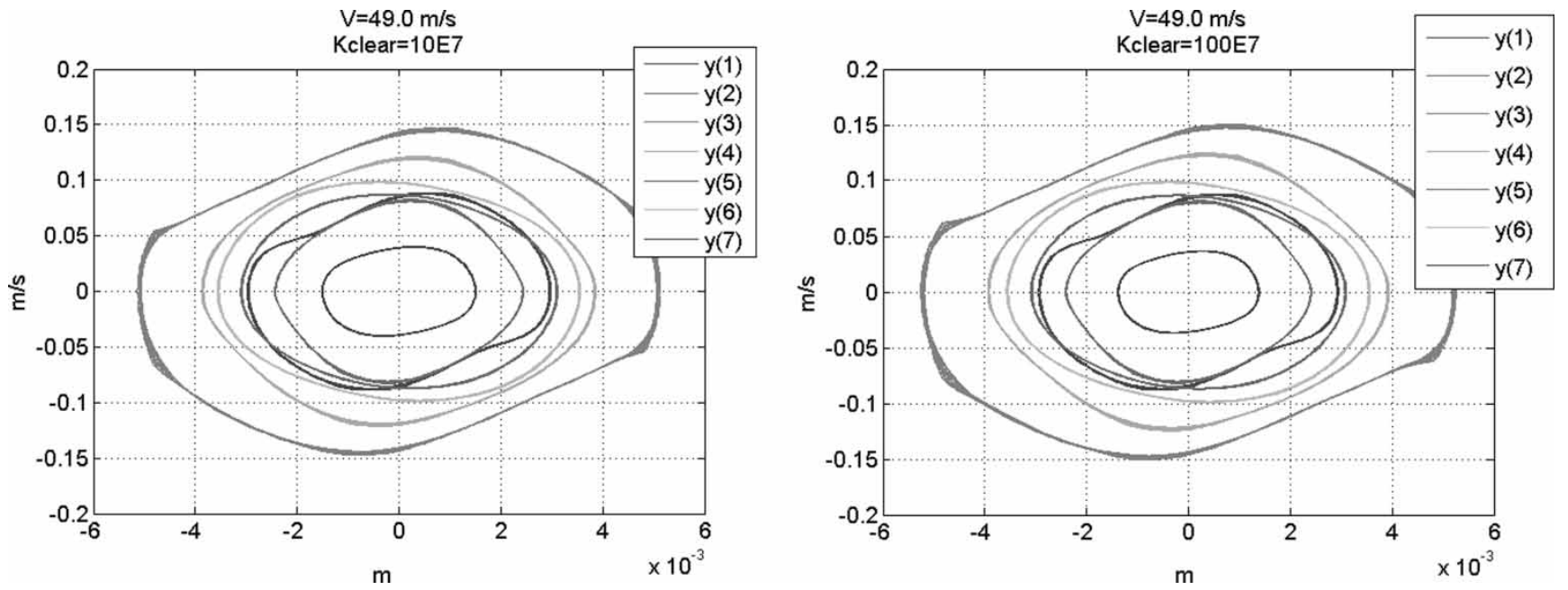

Fig. 20 Effect of Kclear in the lateral oscillation of first bogie $V=49 \mathrm{~m} / \mathrm{s}$ 

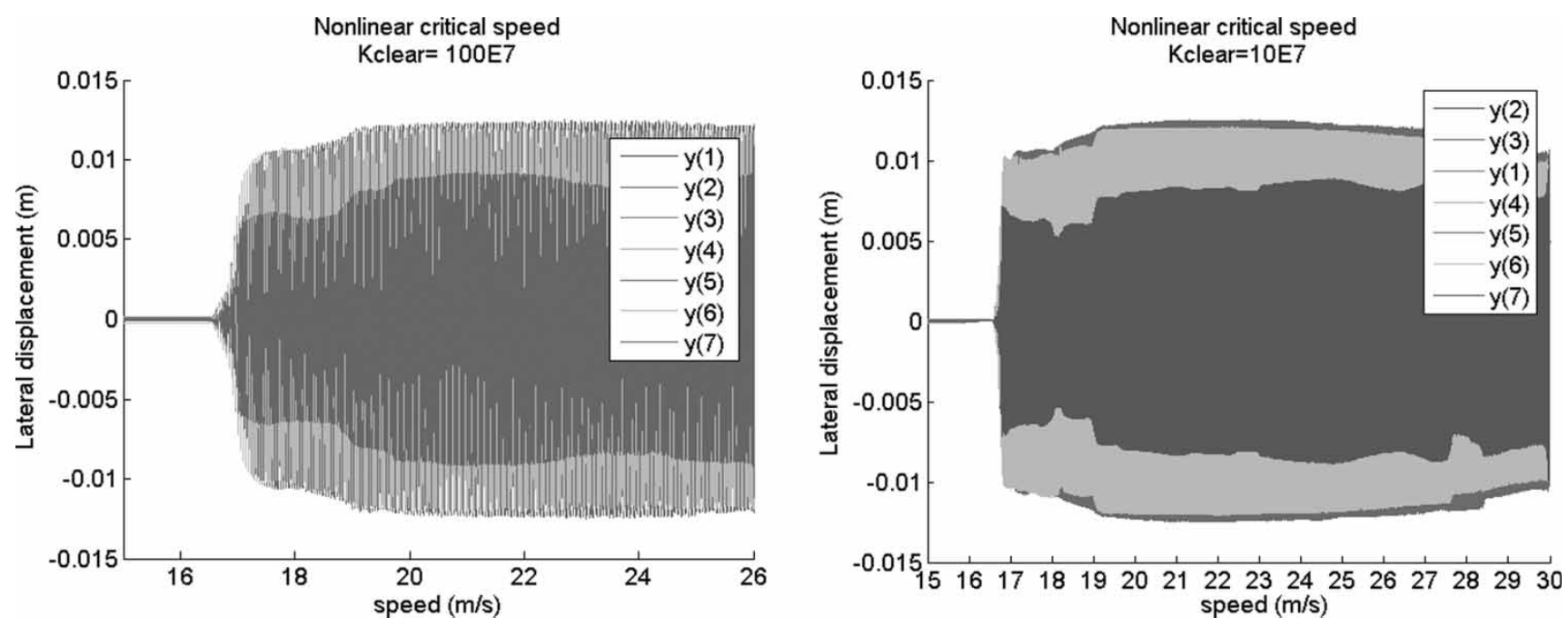

Fig. 21 Effect of Kclear in the non-linear critical speed

in the longitudinal direction, there is $<0.4 \mathrm{~mm}$ deflection, and in the lateral direction there is $<0.5 \mathrm{~mm}$ deflection after impact. Figures 18 and 14 show that in the primary suspension system, deflections after impacts are reduced by 50 per cent. Also, increasing this stiffness changes the oscillations of the first bogie in the wagon. This can be seen clearly by comparing Fig. 19 with Fig. 16. The lateral displacements of the first bogie parts for Kclear $=5.0 \mathrm{E} 7$ and $10.0 \mathrm{E} 7 \mathrm{~N} / \mathrm{m}$ are $<5 \mathrm{~mm}$. The difference between the oscillations of the front and rear bogies that can also be seen in other speeds (compare Fig. 16 and 20) shows that for a more accurate value, one must measure and evaluate Kclear.

Searching for the first saddle node shows that Kclear has less effect on the non-linear critical speed value (Fig. 21). In contrast, the time step for calculations must be less than 0.00001 , and so more time is required for analysing.

\section{CONCLUSIONS}

In this research, the critical speed of the Y25-freight truck has been found to be $61.2 \mathrm{~km} / \mathrm{h}$. Results show that in dynamical responses of this freight truck, there are chaotic limit-cycles and saddle nodes. Also, it has been shown that speeds between 21 and $24 \mathrm{~m} / \mathrm{s}$ that depend on initial conditions, there are two limit-cycles.

The amplitude of oscillations of different parts in limit cycles depends on the vehicle speed. Primary hunting happens between 17.0 and $30.0 \mathrm{~m} / \mathrm{s}$ and secondary hunting after $49.0 \mathrm{~m} / \mathrm{s}$. Increasing the speed increases the frequency of oscillations in limit cycles, but there is no linear relation. Results show that increasing the stiffness in impacts affects calculation time and limit cycles, but the critical speed of the freight wagon is approximately the same for Kclear between 1.0E7 and 1.0E9 N/m. The best value for Kclear can be achieved by means of measurement.

\section{ACKNOWLEDGEMENT}

The authors would like to thank Professor Hans True (DTU of Denmark) for his very useful documents and Dr Moelle (AgreCare Co.) for RSGEO Software.

\section{REFERENCES}

1 Thompson, J. M. T. and Stewart, H. B. Nonlinear dynamics and chaos, 2002 (John Wiley \& Sons, UK).

2 True, H. On the theory of nonlinear dynamics and its applications in vehicle systems dynamics. Veh. Syst. Dyn., 1999, 31, 393-421.

3 Pascal, J. P. Oscillations and chaotic behavior of unstable railway wagons over long distances. Chaos, Solutions Fractals, 1995, 5(9), 1725-1753.

4 True, H. Does a critical speed for railroad vehicle exist? Proccedings of the IEEE/ASME Joint Railroad Conference, Chicago, Illinois, 1994, pp. 125-131.

5 Jensen, C. N. and True, H. On a new route to chaos in railway dynamics. Nonlinear Dyn., 1997, 13, 117-129.

6 Jensen, C. N., Golubitsky, M., and True, H. Symmetry, generic bifurcations, and Ode interaction in nonlinear railway dynamics. Int. J. Bifurcation Chaos, 1999, 9(7), 1321-1331.

7 Xia, F. and True, H. The dynamics of the three-piecefreight truck. Veh. Syst. Dyn., 2004, 41, 212-221.

8 True, H. and Asmund, R. The dynamics of railway freight wagon wheelset with dry friction damping. Veh. Syst. Dyn., 2002, 38(2), 149-163. 
9 Hecht, M. European freight vehicle running gear today's position and future demands. Proc. Instn Mech. Engrs, Part F: J. Rail and Rapid Transit, 2001, 215(F1), 1-11.

10 Kalker, J. J. Three-dimensional elastic bodies in rolling contact, 1990 (Kluwer Academic Publishers).

11 Litzenburger, J. A polynomial approach for the three dimensional wheel rail rolling contact. Veh. Syst. Dyn. 2002, 37(Suppl), 690-701.

12 Dukkipati, R. V. and Amyot, J. R. Computer-aided aimulation in railway dynamics, 1988, section 3.4 (Wheel-Rail Models) (Marcel Dekker, New York).

13 White, R. C., Limbery, D. A., Hedrick, J. K., and Cooperider, N. K. Guideway suspension trade-offs in rail vehicle systems. Report DOT-OS-50107, U.S. Department of Transportation, Washington D. C., 1978.

14 Shen, Z. Y., Hedrick, J. K., and Elkins, J. A. A comparison of alternative creep force models for rail vehicle dynamics analysis. Proceedings of the 8th IAVSD Symposium, Cambridge, MA, 15-19 August 1983, pp. 591-605 (Swets \& Zeitlinger, Lisse, The Netherlands).
15 Keudel, J. Messung der Charakteristik der Primärfesselung eines Güterwagendrehgestells der Bauart Y25 und deren Implementierung in ein MKSModell für die Simulationssoftwarte MEDYNA. Diplomarbeit Fachgebiet Schienenfahrzeuge, TU Berlin, 2003.

16 Kolsch, H. Schwingungsdämpfung durch statische Hysterese. VDI-Fortschritts-bericht, Reihe 11, Nr. 190, Düsseldorf 1993.

17 Jendel, T. Dynamic analysis of a freight wagon with modified Y25 bogies. TRITA-FKT report 1997:48, Kungl Tekniska Högskolan, Royal Institute of Technology, Department of Vehicle Engineering, Railway Technology, Stockholm, 1997.

18 Nielsen, J. Model of the freight wagon bogie Y25 for dynamic analysis in GENSYS, 1996 (Prosolvia Research \& Technology, Gothenburg, Sweden).

19 True, H. and Jensen, J. C. Chaos and asymmetry in Railway vehicle dynamics. Periodica Polytechnica Ser. Transp. Eng., 1994, 22(1), 55-68.

20 Wickens, A. M. Fundamentals of rail vehicle dynamics, 2003 (Swets \& Zeitlinger, The Netherlands). 